\title{
Para pensar la educación política en la educación formal
}

\author{
Thinking About Political Education in Formal Education
}

\section{Pensar sobre a educação política na educação formal}

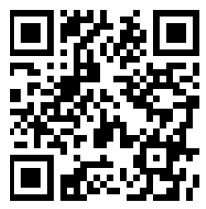

\author{
Ana Corina Fernández-Alatorre ${ }^{1}$ \\ Universidad Pedagógica Nacional \\ Ciudad de México, México \\ acorinafdz@gmail.com
}

Recibido • Received • Recebido: 01 / 02 / 2017

Corregido • Revised • Revisado: 20 / 02 / 2018

Aceptado • Accepted • Aprovado: 16/ 03 / 2018

\begin{abstract}
Resumen: El propósito de este ensayo es compartir las reflexiones en torno al sentido de la política para poder pensar, desde ahí, en la potencialidad de una educación capaz de devolver al sujeto su derecho a tomar la palabra y a actuar; a ejercer de la mejor manera posible su politicidad. A partir de lo que se observa actualmente en países de diversos continentes, en especial aquellos con grandes desigualdades, altos niveles de corrupción y una soberanía vulnerable, se toman, como fuente de reflexión teórica, los textos de Arendt (1997) para dialogar con estudios más contemporáneos que, como los de Bauman (2001), nos invitan a reconocer los muchos rostros devastadores del miedo y su consecuente efecto paralizante. Después de argumentar la necesidad de restituir la política, se abre la reflexión para pensar las implicaciones que esta necesidad plantea al sentido de la educación.
\end{abstract}

Palabras claves: Educación política; ética; ciudadanía; despolitización.

\footnotetext{
1 Psicóloga Social, Maestra y Doctora en Pedagogía por la UNAM. Especialidad en Psicología Social en Nicaragua. Ha realizado trabajos de intervención educativa e investigación en las siguientes líneas: Cambio social, cambio actitudinal, relación escuela y comunidad, así como educación para los medios. Desde hace 20 años realiza investigación en el campo de la formación ciudadana. Ha publicado libros de texto y guías didácticas para la niñez y sus docentes sobre educación cívica, así como artículos, ensayos, capítulo de libros en coautoría e informes de investigación. Entre los libros publicados por la doctora Fernández están: Entre la nostalgia y el desaliento: La educación cívica en México desde la perspectiva del docente y Formación ciudadana e identidad. Voces de la sociedad civil. Entre los textos más recientes, en coautoría está Jóvenes: Entre sus tramas convocantes y sus potencias creadoras. Actualmente es profesora e investigadora de tiempo completo de la Universidad Pedagógica Nacional, en donde ha diseñado y coordinado el campo de Formación para la Convivencia y la Participación Democrática. También en la UNAM imparte el curso Educación para la Democracia en la Licenciatura en Pedagogía. Es miembro de la Red de investigación" Educación, política y Cultura en América Latina, de la red "Memoria Colectiva”, de la Organización Civil “Hacia una Cultura Democrática” y de la Red de Investigación y Estudios Sobre Adolescencia y Juventud. Ha sido miembro del Consejo Consultivo Interinstitucional para el desarrollo curricular de la asignatura de Formación Cívica y Ética en Educación Básica y asesora para el diseño de las Consultas infantiles y juveniles del 2000, 2006 y 2012.
} 
doi: http://dx.doi.org/10.15359/ree.22-2.17

URL: http://www.una.ac.cr/educare

CORREO: educare@una.cr

\begin{abstract}
The purpose of this essay is to share the reflections about the meaning of politics to be able to think, from there, of the potential of a kind of education capable of giving back to the subject the right to take the floor and act, to exercise the politicization in the best possible way. From what is currently observed in countries of different continents, especially those with great inequalities, high levels of corruption and vulnerable sovereignty, the texts of Hannah Arendt (1997) are taken as a source of theoretical reflection in order to bring her into dialogue with more contemporary authors, like Bauman (2001), who invite us to recognize the many devastating faces of fear and their consequent paralyzing effect. After arguing the need to restore politics, reflection is opened to think about the implications of this need for the meaning of education.
\end{abstract}

Keywords: Political education; Ethics; citizenship; depoliticization.

Resumo: O objetivo deste ensaio é compartilhar reflexões e pensamentos sobre o significado da política, e a partir daí, potencializar uma educação capaz de devolver ao sujeito seu direito de falar e agir; para que a politização seja exercida. Pelo que é visto atualmente em países de diferentes continentes, especialmente aqueles com alto nível de desigualdade, de corrupção e com sua soberania vulnerável, os textos de Arendt (1997) são tomadas como uma fonte de reflexão teórica, para o diálogo com os estudos mais contemporâneos, como Bauman (2001), que ajudam a reconhecer as muitas caras devastadoras do medo e consequente, seu efeito negativo. Depois de discutir a necessidade de restaurar a política, a reflexão se dirige a pensar sobre as implicações desta necessidade no significado da educação.

Palavras-chave: Educação política; ética; cidadania; despolitização.

\title{
Introducción
}

Las nuevas formas de dominación han liberado fuerzas que devienen en procesos impersonales esclavizantes que han terminado por desencadenar lo apolítico. Hay un repliegue a la vida privada, al consumo y al olvido que impide pensar las consecuencias de las decisiones que se toman en torno a los asuntos colectivos.

Las democracias de masas están hoy, más que nunca, puestas bajo sospecha ante poderes que se asumen como únicos agentes sociales que simplemente ejecutan los imperativos que les vienen dados por aquella abstracción llamada sociedad (Ávalos, 2015). Esta condición se ve exacerbada por sistemas educativos que han puesto en el centro un productivismo que desvincula al sujeto de la posibilidad de su involucramiento en los asuntos públicos.

Recuperar la política de su letargo para abrir espacios de emancipación de los grandes sectores derrotados, ante los muchos derechos que se ven revertidos, se ofrece como una necesidad urgente que demanda un cambio en las maneras de pensar para impulsar la fundación de nuevas solidaridades que no se agoten en el restringido ámbito de la vida personal. Despoliti- 
zarse supone la total entrega a los asuntos particulares y ello va generando una desensibilización frente a esos otros grupos que quedan fuera del círculo privado. Es así como se fortalece el avance del terror ${ }^{2}$ y la impunidad que termina por naturalizar los abusos.

Tal vez aún estemos a tiempo de hacer de la corresponsabilidad una obligación que devuelva a la política su capacidad real como medio de activar la posibilidad de reconstruir consensos frente a todo lo que afecta a la colectividad de manera imperativa.

El propósito de este texto es compartir las reflexiones en torno al sentido de la política para poder pensar, desde ahí, en la potencialidad de una educación capaz de devolver al sujeto ${ }^{3}$ su derecho a tomar la palabra y a actuar; a ejercer de la mejor manera posible su politicidad, entendida esta, y con base en lo sostenido Calvo (2003), como el conjunto de creencias, sensibilidades, formas de interacción en relación con los debates y tomas de posición en el ámbito de lo público.

A fin de delinear algunos contornos de las condiciones que han gestado la despolitización, se toman como fuente de reflexión los textos de Hanna Arendt, en particular la publicación ¿Qué es la política?, para ponerla en diálogo con estudios más contemporáneos como los de Ávalos (2015), Bauman (2001) y Redacción: Parque Explora (2015), que nos invitan a reconocer los muchos rostros devastadores del miedo y su consecuente efecto paralizante. Siguiendo la línea que Arendt (1977) desarrolla en ¿Qué es la política? y en particular su noción de la acción y de lo público, se argumenta la necesidad de restituir la política. En una segunda parte se abre la reflexión para pensar las implicaciones que esta necesidad plantea a la educación, no para traducirla en nuevos contenidos curriculares, sino para abrir el debate en torno al sentido de una educación que pueda abonar a la repolitización, desde los diversos ámbitos de la intervención educativa.

\section{El hábitat de la despolitización}

Uno de los efectos más contundentes de esta rearticulación de las formas de vida en esta fase del neoliberalismo ha sido el despojo. Pero más allá de la mera desposesión, se han gestado nuevas formas y contenidos de interacción que impactan de manera severa, excluyente y dolorosa, tanto en la familia como en la escuela, la empresa y la comunidad política entera.

\footnotetext{
${ }^{2}$ En países con altos niveles de conflictividad las poblaciones viven en un estado de indefensión que debilita al máximo sus sistemas de segurabilidad. Tal es el caso de algunos países de América Latina que, como Colombia y México, han sufrido los efectos violentos del ejercicio del poder fáctico ejercido por el avance del narcotráfico en buena parte de su territorio nacional.

${ }^{3}$ Se asume en el contexto de este trabajo al sujeto entendido como"el esfuerzo de transformación de una situación vivida en acción libre; introduce libertad en lo que en principio se manifestaba como unos determinantes sociales y una herencia cultural" (Touarine , 2000, p. 22).
} 
doi: http://dx.doi.org/10.15359/ree.22-2.17

URL: http://www.una.ac.cr/educare

CORREO: educare@una.cr

Si alguna vez la condición estatal pudo ofrecer, con cierta racionalidad, un orden que brindó seguridad social, hoy los fundamentos de esta estatalidad no se sostienen más. Desde la perspectiva de Ávalos (2015), el Estado es un proceso relacional que cohesiona a una comunidad. Esa función, fundante de lo estatal, da muestras de agotamiento en el marco de nuevos vínculos de explotación y dominio que fragmentan las comunidades para dar paso a una mera asociación de intereses particulares cuyo fin principal es la ganancia de unos pocos grupos.

Ya desde hace más de cuarenta años se alertaba frente a las señales inquietantes de la fragilidad de una civilización que aspiró a la "libre competencia" sostenida en la producción irracional de mercancías y se estrelló muy pronto con todo lo contrario: los grandes monopolios industriales, comerciales y financieros fueron fortaleciéndose como los sujetos de poder realmente existentes, al apropiarse, cada vez más, de espacios vitales donde lo público se degrada. Así, la apertura económica, la desregulación laboral, el control ideológico y militar que estigmatiza las alternativas han gestado el hábitat de una condición posdemocrática. Añade Ávalos (2015):

[Esto ocurre sobre todo en las áreas] que requieren la legalización de lo ilícito. En esas condiciones deja de existir el Estado propiamente dicho el sentido que anima a las actividades gubernamentales ya no es el del mantenimiento del orden social conjunto a partir de una racionalidad política, sino la acumulación de ganancias "aunque parezca" el interés de todos. (p. 15)

Esta condición se exacerba en territorios que cuando dejaron de ser colonizados mediante una soberanía declarativa, constituyeron Estados débiles y subalternos que tendieron a garantizar la producción de sus bienes en aras del beneficio de una totalidad sistémica de un modo que ni los gobiernos progresistas fueron capaces de detener.

Como un ejemplo reciente, Santos (en León y Delacoste, 2016) señala los casos de Brasil y de Argentina, que aprovecharon el alza de precios que se produjo con el llamado consenso de los commodities y debido al impulso del desarrollo de China, optaron por profundizar el modelo de desarrollo extractivista, con el fin de destinar algo de la renta que ofreció esta alza de precios de las materias primas, para hacer algo de redistribución social. Al no cambiar el modelo económico, los ricos y las oligarquías se siguieron enriqueciendo.

Los bancos, por ejemplo, nunca ganaron tanta plata en Brasil como en los tiempos de Lula, pero, como los precios [del petróleo] eran altos, quedaba un excedente significativo para hacer una redistribución sin precedentes. Por medio de mecanismos como bonos, becas familia y otras políticas sociales, se logró que más de 45 millones de personas salieran de la pobreza, lo que es un hecho político importante. Pero no era el socialismo, porque dependía totalmente de los precios internacionales, en cuya formación Brasil no incide de ninguna manera. (Santos, en León y Delacoste, 2016, párr. 5) 
La continuidad del modelo económico trajo consigo la del modelo político que siguió siendo colonial y quedó en evidencia una vez que los commodities, al bajar de precio, dejaron a los gobiernos sin la posibilidad de garantizar las políticas públicas y la llamada primavera de América del Sur llegó a su invierno. Estos gobiernos, al profundizar el agronegocio, generaron las condiciones para incrementar el despojo de poblaciones y la contaminación del agua en "complicidades extrañas con los ejércitos privados que existen, con organizaciones paramilitares que matan a los indígenas y a los líderes campesinos por todo el continente, mientras estos gobiernos miran hacia otro lado. Por eso el ciclo se agotó" (Santos, en León y Delacoste, 2016, párr. 7).

No hubo durante estos gobiernos populares cambios sustanciales, ni en el sistema político ni en el de la comunicación y, desde luego, ni en el sistema fiscal. Ello dejó atrapados a los partidos en la lógica impuesta por las oligarquías y las derechas tradicionales.

Mientras tanto, se ha ido fortaleciendo la tendencia generalizada de pensar en la política como aquello que hacen los partidos. Es este un modelo que ha construido la ciencia política hegemónica ${ }^{4}$ en el seno de prácticas gubernamentales que cancelan la separación real entre los poderes. A ello habrá que sumar la desafección de la mayoría de la ciudadanía frente a las grandes decisiones que quedan a merced de la tasa de ganancia empresarial legal e ilegal. De ahí que, como subraya Monedero (2013), hoy se asigne mayor importancia al diseño electoral que a la construcción de sentido.

La democracia ha quedado reducida a la discusión entre las élites encargadas de reformular el lenguaje y los procedimientos para gestionar la "construcción de mayorías políticas". La ciudadanía ha terminado por ser la gran ausente frente a procesos de toma de decisiones cuyos entramados resultan cada vez más inaccesibles a la comprensión de la gente común “Tenemos democracia, pero no tiene densidad alguna ... 'Vota y no te metas en política'. Y la política deja de ser conflicto para entenderse como un ámbito técnico donde los expertos encontrarán soluciones" (Monedero, 2013, p. 111).

En un mundo donde se naturaliza la crisis económica, el cinismo político y desesperanza, la ciudadanía de a pie vive hoy, desde la desconfianza en las instituciones y en los otros sujetos, esta condición de posdemocracia donde, en el mejor de los casos, queda como mera espectadora de una saturación audiovisual desplegada por el imaginario hegemónico consumista que se asienta en la centralidad de la "pospolítica", es decir, en la negación/ neutralización del conflicto. Podemos hoy presenciar un creciente alejamiento de las personas con respecto a los procesos de decisiones que involucran consecuencias para la mayoría. Al respecto, Yuren (2013a, p. 113)

\footnotetext{
${ }^{4}$ Esta construcción de la ciencia política hegemónica se ha sostenido, señala Ávalos, en el paradigma científico y tecnológico de occidente, hoy vigente, que ha logrado imponer una forma de entender la relación entre el ser humano y la naturaleza que genera la sumisión al productivismo desenfrenado, al consumismo extremo y, en última instancia, a la cosificación, la pérdida del sentido de la vida y la deshumanización (Ávalos, 2015, p. 21).
} 
doi: http://dx.doi.org/10.15359/ree.22-2.17

URL: http://www.una.ac.cr/educare

CORREO: educare@una.cr

destaca que ello"hace que dependan cada vez más de los medios para obtener las informaciones que les permitan enfrentar los problemas y participar en la vida social".

Al público espectador, cliente potencial del consumo de opciones para el voto, se le nutre con información debidamente procesada, de modo que no pueda percibir la potencialidad del conflicto como fuente de acuerdo y transformación colectiva a la que tiene derecho mediante su participación.

Cuando la voz de las personas "'sin': sin tierra, sin techo, sin trabajo, sin patria, sin papeles, sin familia, sin escuela, sin esposa, sin esposo, sin hijos, sin padres, sin derechos, sin seguridad social, sin identidad, sin existencia" (Ávalos, 2015, p. 13), logra romper la barrera de los medios hegemónicos de comunicación, se le asigna el lugar del homo sacer (Agamben, 2006), quien es asesinable y se expone a la exterioridad de la sociedad: Su muerte, su dolor, se explica, se justifica desde la percepción de su condición de paria y, por ello, se tolera como normal su exterminio. Con ello se va creando una nueva sensibilidad "desensibilizada" que reconfigura el sentido de pertenencia a la especie en aras de un individualismo implacable. Estas múltiples figuras de los grupos desposeídos devienen en los medios de información en agentes de conflictividad que hay que eliminar, acallar mediante la desmentida de los motivos de su indignación. No hay ahí lugar para la pregunta que les devuelva su lugar de sujetos de derecho a los ojos y oídos del público espectador al que se le infantiliza de manera que, como la niñez, necesita que le cuenten siempre el mismo cuento, para no caer en la ansiedad (Monedero, 2013).

Hace falta, como señala (Žižek, 2010), poner bajo sospecha la insistencia de alarma de las "buenas conciencias" frente a la violencia, que no hace más que invisibilizar su verdadera fuente: La pobreza, el despojo, la incertidumbre, la corrupción y su hermana, la impunidad. Al parecer, frente a ello no hay voz de alarma, eso puede esperar, tanto que, al percibirse como lo "normal", termina por convertirse en "parte del paisaje" $y$, al desdibujarse como conflicto, pierde la fuerza para desplegar la indignación, la capacidad de acción y, con ella, su potencialidad creadora.

Ya, desde hace tiempo, asistimos a un hondo proceso de despolitización bajo las coordenadas del miedo y sus consecuencias: la desconfianza, por un lado, y, por el otro, la risa antioficial, aquella que banaliza toda acción política real para desembocar en una especie de misticismo emocional que cancela la posibilidad de reconstrucción de lo público.

Bauman (2001) explica cómo el miedo cósmico frente a lo inmensamente grande y poderoso, utilizado por todos los sistemas religiosos para negar a la persona y su conciencia, fue rediseñado, mediatizado, domesticado, para fabricar el miedo oficial a través del embudo de la ley. Hay un momento constitutivo de todo poder terrenal que, añade Bauman (2001), de todo poder terrenal que se sostiene en la negación, la mentira, la violencia y el miedo, donde "la esencia del miedo político no es tanto la preocupación frente a un peligro inminente y concreto como la sensación de absoluta vulnerabilidad frente al otro" (p. 68). 
El miedo ciudadano empuja a la sociedad a un sometimiento autoinfligido y de impotencia que acaba por sacralizar al poder como instancia redentora.

Los usos comerciales y políticos del miedo son inagotables. Hay una obsesión insaciable por la seguridad que desata la desconfianza mutua y siembra el cultivo de la sospecha permanente sobre el otro sujeto. Desde ahí se trazan las fronteras que sostienen y nutren prejuicios mutuos (Bauman y Donskis, 2015).

Tan solo para ilustrar con cifras estos efectos del miedo que obliga a refugiarse de lo externo en lo individual y su entorno inmediato, lo familiar, la vida privada: México, desde el 2005 , quedó casi $30 \%$ por debajo del nivel promedio de confianza interpersonal en la Encuesta Mundial de Valores (2005) y, para el 2014, ya solo 3 de cada 10 personas poseían confianza interpersonal de acuerdo con los datos revelados por la Quinta Encuesta Nacional de Cultura Política y Prácticas ciudadanas de 2012 (Segob, Inegi, 2012) y en el Informe país sobre la calidad de la ciudadanía en México (IFE, 2014).

La otra cara del miedo que paraliza la acción política es la risa que es, en realidad, una forma audible del miedo. Lejos de ser un signo de rebeldía, es el signo de reconciliación con el miedo, dice Bauman (2001) al referirse a la banalización del conflicto donde los actores quedan todos por igual descalificados y ridiculizados sin opción para repensar la situación, para problematizarla, para replantearla e inscribirse en su reformulación. Esta risa que borra la posibilidad de transformación no es más que la clara señal de sumisión al miedo"...y aceptación de la imposibilidad de vencerlo, decisión de tomárselo a la ligera, intención de domesticarlo y usarlo en beneficio propio" (Bauman 2001, p. 71).

Al colapsar las instituciones que eran garantes de la vida y del bienestar, queda el individuo a la intemperie para hacerle creer que es libre de crear y sacar lo mejor de sí para ponerlo en circulación en el mercado. De esta manera es reconducido hacia explicaciones místicas para las que existen igualmente soluciones místicas (Ávalos, 2015). Es el individuo en solitario frente al poder superior, supraterrenal que dejó de depositar su esperanza en el encuentro con los otros seres para resolver asuntos comunes. De ahí que Arendt (1997) nos advirtiera que, lo que da un tono peculiar al prejuicio contra la política, es su huida hacia la impotencia.

Lejos de asumir esta impotencia frente a lo dado y desde las reflexiones sobre el fin del ciclo de los gobiernos populares en América del Sur, Santos (en León y Delacoste, 2016) abre un imaginario con la consigna de "empezar de nuevo", que se acepta aquí como una provocación para la necesaria reflexión en torno a la esfera política, sus posibilidades de resistencia y sus implicaciones para una práctica educativa que pueda hacer aportes a la indispensable transformación de formas de entender la vida en común y, con ello, la apuesta por construir nuevas formas de estatalidad. 
Para ello y frente a la idea de la ausencia de alternativas, habrá que dar lugar al escepticismo tal y como lo entiende Beck (1998): Un escepticismo que abre de nuevo toda posibilidad de recolocar el conocimiento, la fe, la sociedad y la crítica, pero en una dimensión más acotada que permita abrir otras tentativas más revisables que sean objeto de aprendizajes capaces de conducirnos a lo insospechado. Frente a la fatalidad que supone asumir la ausencia total de alternativas, habrá que usar el escepticismo becktiano que asigna un lugar a lo que queda fuera del control oficial, a lo imprevisto, a lo probable, a lo posible, para posicionarse de otra manera frente al miedo y no quedar atados a la resignación.

Eso es lo que Santos (2014) planteó a la juventud de México:

La contingencia de nuestra vida y de nuestra sociedad está dominada por dos emociones: el mied o y la esperanza. Sepan Ustedes que esta violencia desatada se dirige a su resignación, dominados por el miedo $y$, sobre todo, por el miedo de la esperanza. Los poderosos criminales saben que sin esperanza no hay resistencia ni cambio social. Sabemos que es difícil escapar al miedo en condiciones tan dramáticas como las que viven. El miedo no se puede eliminar, pero lo importante es no rendirse al miedo, sino tomarlo en serio para poder enfrentarlo y superarlo eficazmente, a eso le llamamos: Esperanza. (párr. 3)

Una esperanza que se sostiene en la apuesta por la resistencia a las múltiples formas de control que se despliegan por parte de los diversos poderes que cancelan el futuro de millones de niñas, niños y jóvenes que constituyen la mayoría del precariado (Butler, 2004).

\section{La necesidad de restituir la dimensión política}

Ya Arendt (1997) nos advertía acerca de cómo, al irse perdiendo los hilos de la tradición, se han desdibujado aquellos significados que sostienen el reconocimiento de nuestra condición de seres vulnerables, mortales. Somos individuos, sí, pero sobrevivimos en grupo. El ser humano no es autárquico, depende para su existencia, de otros individuos. Por eso su cuidado concierne a todos. Sin ello, la convivencia sería imposible. Dussel (2014), en sus 16 Tesis sobre economía política, nos recuerda que siempre fuimos comunidad. Ahí está, como prueba, la eticidad de muchos pueblos originarios que nos han dejado, como legado, nociones que aluden a la inevitabilidad de la vida en común. Tal es el caso, como ejemplo, de la noción de origen quechua, de Sumak Kawsay, donde la vida se entiende en términos de dignidad, de plenitud y las personas constituyen solo un elemento de la Pachamama o "madre tierra". Desde ahí se promueve la idea de tomar solo lo necesario para perdurar y no para dominar o controlar a los otros seres. Otra noción que alude a este tipo de eticidad es, por ejemplo, el término ubuntu que proviene de las lenguas sudafricanas zulú y xhosa y revela el lugar que se da al hecho de que cada persona es lo que es en función de todas las demás. Define una persona ubuntu en los siguientes términos: 
Está disponible para los demás, respalda a los demás, no se siente amenazado cuando otros son capaces y son buenos en algo, porque está seguro de sí mismo ya que sabe que pertenece a una gran totalidad, que se decrece cuando otras personas son humilladas 0 menospreciadas, cuando otros son torturados u oprimidos. (Casa África, s. f., párr. 3)

Entre indígenas de los Andes existe la palabra ayni, referida a un sistema de trabajo de reciprocidad familiar y así podemos encontrar muchísimos ejemplos de este legado a lo largo de los muchos territorios colonizados en los que queda, de manera muy marginal, esa forma de entender la vida.

En su análisis del imaginario, como el lugar de la creatividad social en las utopías colectivas, Lizcano (2010) cuestiona la insistencia en la primacía del sujeto sobre la que se erige todo un culto al individuo, y rescata del tojolabal frases como "kala awab' yex" que se traduciría literalmente como: "Yo dije, ustedes escucharon" explicado por Lenkersdorf (citado por Lizcano 2010), "como una lengua intersubjetiva, en la que se expresa un imaginario y unas formas de vida, unos hábitos necesariamente intersubjetivos" (p. 71). Basta con recordar la narración que se hace en el Popol Vuh (Abreu, 2007) sobre la creación de las sucesivas formas de la humanidad para encontrar que la palabra creadora es una palabra compartida en el marco de las conversaciones entre miembros de un concejo. Se despliega, así, en la lengua, en su gramática, un imaginario que refiere a la diversidad de recursos a partir de los cuales se dialoga y que nutre la riqueza de las más variadas formas comunitarias de convivencia (Lizcano, 2010).

Estas huellas, estas señas aún vivas de las antiguas civilizaciones están ahí para recordarnos que como individuos aislados somos puro fragmento. Por eso necesitamos de la política como la vía para reconstruir el escudo protector de un destino común frente a la oferta neoliberal de dejar de pensar, dejar de actuar y luego dejar de emocionarnos para que la alegría evanescente quede en manos de consumo tras consumo de ansiolíticos, de drogas, de ropas y de artilugios inútiles, de sectas, de odios, de televisión (Monedero, 2013).

Santos (en León y Delacoste, 2016) coincide con Monedero (2013) al señalar que los partidos ya no pueden, de ninguna manera, tener el monopolio de la representación. Por ello reclaman nuevas formas a través de la democracia participativa ${ }^{5}$, de la ciudadanía, de los movimientos sociales que tienen que tener una palabra fuerte en la renovación política, es decir, que tendremos que crear otras figuras políticas como los partidos- movimientos.

Si bien la política se ha eclipsado en nuestros tiempos, también hay razones para "pensar que no todo está perdido y que la política se puede recuperar de su letargo"(Ávalos, 2015, p. 28).

\footnotetext{
${ }^{5} \mathrm{Al}$ respecto se puede consultar el papel democratizante de la sociedad organizada a través de algunos movimientos sociales y de algunas organizaciones civiles de desarrollo social (Fernández, 2010).
} 
doi: http://dx.doi.org/10.15359/ree.22-2.17

URL: http://www.una.ac.cr/educare

CORREO: educare@una.cr

Cuando hablamos de política nos referimos a aquel ámbito de lo social vinculado a la definición y articulaciones de metas colectivas de obligado cumplimiento que "busca recomponer los fragmentos rotos de la polis?" (Monedero, 2013, p. 19).

La política supone, en primer lugar, el reconocimiento de nuestra interdependencia en tanto que si nos dispersamos, si nos enfrentamos, si nos dividimos, terminaremos pereciendo. En segundo lugar, implica dar lugar al conflicto social como algo que nos atañe. De otro modo siempre nos seguirá acechando, nos demos cuenta o no.

Politizar algo es hacer consciente el conflicto inevitable entre los intereses de los individuos y grupos y los del resto del colectivo. El ser humano se mueve por el deseo, impelido a su vez por la imitación, pero ese deseo -el que sea- sólo se puede cumplir en la vida social. De ahí que el conflicto afecta cada rincón de la vida social. (Monedero, 2013, p.101)

La negación del conflicto puede llevar al efecto perverso del máximo conflicto, por eso el reclamar nuestra parte en las decisiones colectivas dentro del juego frente a un conflicto es recuperar la dimensión política. Despolitizarse es particularizar, es dejarde pensarlas implicaciones colectivas de un asunto. Repolitizar supone, entonces, recuperar la capacidad de irrupción como comunidad consensual, como potencia para la transformación de aquellas instituciones que no se rigen por principios de normatividad justos. El consenso, no como imposición homogenizante, sino como producto de la deliberación que da lugar a la diferencia, es la fuente de validez política, de legitimidad, de reconocimiento de que la última sede del poder radica en esta comunidad de consenso sin olvidar, nos recuerda Dussel (2014), que el criterio fundamental de toda comunidad política ha de radicar en la defensa de la vida El poder es la voluntad de vida de una comunidad. El poder es aquí entendido, desde Spinoza (citado por Cullen, 2003, p. 36), como potencia que se opone al proyecto de "una sociedad de ciudadanos tristes, con potencia de actuar disminuida, sometidos a causas externas, sin poder transformar las pasiones pasivas en activas, es decir, siervos" (Cullen, 2003, p. 37). En esa misma línea, Arendt (1997) sostiene que el poder es resultado de la acción conjunta que se comparte en un determinado tiempo y espacio entre seres humanos que, siendo diferentes, son iguales. Este poder surge, entonces, de la actuación conjunta de muchos, por eso no puede ser detentado por un solo individuo como sucede con la violencia. Por ello hace falta fundar un poder en la horizontalidad de la igualdad humana. Ese fue el mensaje de Arendt (1997) para las futuras generaciones.

\section{La acción y la emergencia de lo público}

Cabe recordar que, desde el planteamiento de Arendt (1997), la teoría no es la que debe orientar la acción; su función es indicarnos cómo comprender, no la de enseñarnos a cambiar el mundo. Cambiarlo es cosa de quienes aman actuar concertadamente. Esa no es tarea del

Ana Corina Fernández-Alatorre

Los artículos de la Revista Electrónica Educare del Centro de Investigación y Docencia en Educación de la Universidad Nacional, Costa Rica, se comparten bajo términos de la Licencia Creative Commons: Reconocimiento, No Comercial, Sin Obra Derivada 3.0 Costa Rica. Las autorizaciones adicionales a las aquí delimitadas se pueden obtener en el correo: educare@una.cr 
solitario trabajo de los teóricos y las teóricas. Arendt (1997) arremete contra los esencialismos y los a priori de la política que plantea la filosofía, pues esta resulta de la práctica de la vida y escapa al entendimiento de la ciencia política de corte empirista que es incapaz de comprender y, por supuesto, explicarla desde sus restringidos marcos teórico- filosóficos.

Ya desde finales de los años 50 Arendt (1997) nos advertía que la política ha sido gradualmente sustraída a la ciudadanía que ha quedado reducida, en el mejor de los casos, a la condición de animal laborans, ${ }^{6}$ al que le es negada la acción que, junto a la palabra, permite el ingreso a un mundo donde ya están presentes los otros sujetos; donde en lugar de ser algo, podemos ser alguien.

En el marco del reconocimiento de la desgracia que ha producido el autoaniquilamiento de la política que se precipita a un callejón sin salida, Arendt (1997) se pregunta por el sentido de la política y responde qué es la libertad. La política, entonces, no es un fin, sino un medio, una necesidad ineludible, pues su misión y fin es asegurar la vida en su sentido más amplio, más humano, más digno.

El espacio público, nos advierte Arendt (1997), se va deshabilitando y con ello deja de iluminar en tanto deja de hacer visible quién reduce a las personas a una condición de objeto administrable, regulable. Hay aquí un reconocimiento de una especie de muerte del sujeto que en virtud del progresivo adelgazamiento de lo público se aísla al individuo y se le abandona a un proceso de desgarramiento de sus relaciones sociales que provocan el avance de un desierto y su consecuente pérdida de mundo. Las tormentas de arena de los totalitarismos, añade, han debilitado dos capacidades que permitían transformar el desierto: La facultad de la pasión y la facultad de la acción.

Arendt (1997) parte de una premisa sustancial en su pensamiento: El ser humano existe solo como pluralidad y en la pluralidad, ya que no hay un pensamiento originario que dé la clave de toda la historia, lo que es originario es la pluralidad. De ahí que el mundo sea percibido desde las distintas posiciones que ocupamos en él y solo hablando es posible comprender, desde todas las posiciones, cómo es realmente este. Desde esta perspectiva, el mundo es entendido, entonces, como lo que está entre nosotros y nosotras; lo que nos une y lo que nos separa. El sentido común es una cualidad producida en común, es nuestro sentido del mundo y es el que nos constituye en nuestra intersubjetividad. Es en el mundo, en tanto espacio que se abre entre las personas cuan-

\footnotetext{
${ }^{6}$ La noción de animal laborans fue desarrollada por Arendt (1993) en su libro La condición humana, donde plantea las tres actividades fundamentales del ser humano: labor, trabajo y acción La actividad de labor es entendida como aquella que lleva a cabo para producir lo que necesita para la sobrevivencia. Esta actividad no se realiza en libertad, pues está atravesada por la necesidad. En el trabajo el ser humano construye, fabrica y en la acción crea en el marco de su interacción con los otros, lo cual le posibilita desplegar sus potencialidades para la vida pública y así afirmarse en la creación del mundo.
} 
doi: http://dx.doi.org/10.15359/ree.22-2.17

URL: http://www.una.ac.cr/educare

CORREO: educare@una.cr

do coinciden, donde tienen lugar los asuntos humanos. En contra de las concepciones esencialistas subraya que el mundo y las catástrofes que tienen lugar en él no le suceden a ser humano a la esencia de este, pues el mundo y las cosas que suceden en él no expresan una producción impuesta al exterior desde la esencia. Estas catástrofes son el resultado de lo que los grupos humanos son capaces de producir. Algo que no son ellos mismos y luego se cosifica en un mundo de cosas (alienados) y en el que actúan y los condiciona. Por ello, el punto central de la política es por el mundo y no por el ser humano, así en abstracto y universal, pues el mundo, en tanto que es el espacio que nos une y nos separa, no se transforma cambiando a las personas, sino modificando el mundo a través de la acción en lo público. A través de la transformación de aquello que invoca a la comunidad de cosas que nos unen, nos agrupan y nos separan a través de relaciones que no supongan fusión como suele suceder en los cuerpos políticos que se sostienen en el modelo de parentesco como las fraternidades, porque en ellas lo diverso se convierten en uno y con ello se obtura la posibilidad de representatividad mediante el ejercicio de un poder que se ejerce como dominio que niega la diferencia. Conviene aquí recurrir a la noción arendtiana de comunalidad como algo que está en permanente construcción a través de la palabra, de la deliberación. Lejos de representar un sentido de bien que se impone desde una supuesta búsqueda de homogeneidad, el bien de una comunidad es, en primer lugar, un bien plural, pues refleja las diferencias entre las personas, sus distintos intereses y opiniones. El rasgo de comunalidad de estos intereses es algo que construyen los sujetos mediante la solidaridad y la reciprocidad, de modo que este bien común se construye únicamente a partir de la deliberación que se suscita en el marco de la confrontación de las diferencias; en aras de elaborar, colectivamente, la articulación, los distintos intereses, mediante procesos de mutua persuasión al interior del debate y la argumentación sostenida en la capacidad de juicio político que todo ser humano puede desarrollar como resultado de su experiencia del mundo, entendido este como lo que es común a muchas personas, que yace entre ellas y solo es comprensible hablando entre ellas, intercambiando sus perspectivas, pues es únicamente en la libertad de conversar que el mundo surge en su objetividad posible.

Así como no existen los a priori de la política, para Arendt (1997) tampoco lo público preexiste a la acción, pues depende de la fulguración de esta, es decir, poco más que un resplandor que emerge de entre unos actores acosados por su imprevisibilidad, por sus voluntarias y libres acciones incapaces de imponer sus criterios, sino es juntamente con sus acompañantes. La función de lo público es arrojar luz, donde sea posible, sobre aquello que sucede a los seres humanos, a fin de que puedan aparecer, hacerse visibles y revelar quiénes somos. El espacio público se constituye, así, en el lugar de encuentro para compartir sus relatos y dialogar para actuar y luchar juntos buscando su propio bien en el seno de relaciones que fortalezcan esa capacidad de acción. Lo público se gesta, entonces, en la acción misma y se desvanece en su ausencia. La evanescencia radica en su irrepetibilidad. 
En contra de la restringida idea de que política es el arte de gestionar los conflictos, los tiempos y las posibilidades, Arendt (1997) sostiene que lo político es el ámbito donde los seres humanos son primariamente activos en virtud de que "Los humanos tenemos el extraño poder de irrumpir en los procesos naturales, sociales e históricos puesto que la acción hace aparecer lo inédito"(p. 19). Esta condición de seres primariamente activos no es exclusiva del agente político formal y visible"Todos somos agentes, actores, pero no dueños autores de los virtuales sentidos de nuestras acciones" (Arendt, 1997, p. 23). Los seres humanos solo son libres mientras actúan. Esta acción concierne al estar entre otros: inter- ese. De ahí que no sostenga la preexistencia del sujeto político: aislado, soberano y autónomo. El que inicia la acción con espontaneidad está aún en un estadio prepolítico. Toda acción supone concertación, en tanto que es imposible actuar sin amigos y camaradas de confianza. La acción solo se realiza, se completa, con otros iguales. Si el individuo existe solo como pluralidad y en la pluralidad, solo en la política, en el poder compartido, en el compromiso, su existencia se vuelve auténtica, pues deja de ser mero predicado, mero objeto.

La acción no supone solo una dimensión utilitarista, va mucho más lejos: la acción que tiene este poder de interrumpir los procesos naturales e históricos permite que aparezca lo inédito, pues un acto, en este sentido, es un momento de ruptura con lo dado, con el pasado. Actuar, entonces, para Arendt (1997), "es inaugurar ... aparecer por primera vez en público ..., añadir [lo] propio al mundo" (p. 20) que deja sentado un nuevo comienzo, el inicio de una cadena de acontecimientos. Esta acción únicamente es política cuando va acompañada de la palabra que vincula a los individuos entre sí y, por ello, le confiere sentido y durabilidad al mundo y dice nuestra responsabilidad en él.

\section{La educación y la posibilidad de la repolitización}

La crisis educativa no es más que la expresión de un sistema civilizacional que ha dejado de ofrecer respuestas creativas frente al dislocamiento del sistema mundo.

Es la crisis de una educación racionalista que no puede revertir la irracionalidad de una humanidad que ha llegado al límite de la creatividad que es posible haciendo uso exclusivo de las potencias del pensamiento abstracto. (Mazorco, 2010, p. 1)

Ya desde el siglo pasado no son pocos los estudios que, al hablar de la crisis de la educación, nos han advertido acerca de los efectos devastadores de políticas educativas que desdeñan la necesidad no solo de mantener viva la aspiración a la democracia, sino de desarrollar las capacidades para que esta se constituya en uno de los ejes de articulación de modos de vida.

No muy lejos de lo que ya anunciaba Arendt (1997) a mediados del siglo pasado, Nussbaum en (Redacción: Parque Explora, 2015) plantea: 
doi: http://dx.doi.org/10.15359/ree.22-2.17

URL: http://www.una.ac.cr/educare

CORREO: educare@una.cr

Si esta tendencia continúa, las naciones de todo el mundo pronto estarán produciendo generaciones de máquinas útiles, en lugar de ciudadanos completos que puedan pensar por sí mismos, criticar la tradición y entender el significado de los sufrimientos y logros de otra persona. (párr. 2)

Desde la lógica de mantener la competitividad en el mercado global, se han ido eliminando, de la educación básica y superior, las humanidades y las artes de los planes de estudio de casi todas las naciones del mundo. Al poner en el centro de los fines de la educación el crecimiento económico, se van diluyendo las habilidades creativas, las de pensamiento crítico transformador y aquellas que permiten imaginar comprensivamente la situación del otro ser, de todas las otras personas, para trascender las lealtades locales, para acercarse y sentir que se implican en los problemas tanto nacionales como mundiales. Esta no implicación, además de aniquilar el mundo, puede acabar con la capacidad humana para configurarlo. Los paradigmas que ponen en el centro al individuo, así en solitario y como sujeto productor y de consumo, provocan que se desentienda y se coloque frente a los peligros "exteriores" en una posición de elución, desde una falsa interioridad, donde como máximo solo pueda reflexionar en la catástrofe, pero no actuar ni cambiar nada.

Cabe, entonces, una vez más, preguntarse: Educar, ¿para qué?

Siguiendo el hilo ofrecido por Arendt (1997) en al apartado anterior, el sentido de la educación radica en la necesidad de formar para que el sujeto aprecie y desarrolle su capacidad de habitar entre los otros seres; para aparecer y decir quién es, pues es desde su aporte que, con los otros individuos, hace el mundo.

No se trata de plantear aquí nuevos contenidos, sino, dado el caso, de detenerse a pensar, una vez más, en los fines del aprendizaje de esos contenidos que han de ofrecerse en función de brindar referentes para desarrollar la capacidad de pensar el mundo y luego retornar a él responsabilizándose desde espacios que den lugar al pluralismo, a ese reconocerse, frente, desde y con las otras personas; en la acción real. En la actualidad no hay contenidos que dejen claro, por ejemplo, que el Estado no es de nadie, pues es de todas las personas y, por ello, nadie se lo puede apropiar.

Arendt (1997) es muy enfática al señalar que no existe una esencia política, de hecho, no hay esencia del ser humano y lo político, por tanto, no es parte de esa supuesta esencia. Por ello no existe tampoco la aristotélica idea del ser humano como Zoon Politikon. Lo político no es una exigencia de la naturaleza humana como el hambre y el amor, pues "empieza donde acaba el reino de las necesidades materiales [labor] y la violencia física" (p. 71). El ser humano es apolítico al nacer, pues la política nace en el entre las personas. Por ello se opta aquí por hablar de sujeto. Un sujeto que ha de ser formado con capacidad de juicio y de acción. El sujeto que construye mundo entre los otros individuos al aparecer con su aporte desde un quien que asume su libertad y esta solo existe en el ámbito del entre de la política. 
En general, los sistemas educativos han soslayado ${ }^{7}$, a veces de manera velada o por franca omisión, la necesidad de formar el juicio político. En el mejor de los casos, se ha puesto el acento en la formación de un juicio ético que deja sin sustento la necesidad del involucramiento con lo público.

Hace falta mucho más que reformatear al ser humano en aras de las necesidades de un crecimiento económico que demanda la producción de individuos competitivos, eficaces, reflexivos, emprendedores y capaces de autogestionar su individualidad.

En definitiva, la supuesta autodeterminación personal que se pretende en tiempos del neoliberalismo no significa más que una forma de control más económica del individuo, porque él mismo se autocontrola, mientras cree que está ejerciendo su soberanía individual. (Mazorco, 2010, p. 2)

Es del todo inaceptable la idea de que la responsabilidad social recaiga "exclusivamente en la moralidad de los sujetos sin atender a la ausencia de las condiciones del ejercicio ciudadano" (Castro, Rodríguez y Smith, 2014, p. 18). Por ello hace falta crear las condiciones para desarrollar las potencialidades del sujeto de la agencia en el sentido en que lo sostiene Bauman (2002, citado por Yurén, 2013b): "la capacidad de influir sobre las circunstancias de la propia vida, formular el significado del bien común y hacer que las instituciones sociales cumplan con ese significado" (p. 10).

El desafío radica, entonces, en pensar un sentido de la educación que asuma la necesidad de desarrollar un juicio político capaz de orientar la acción que solo será política cuando vaya acompañada (Arendt, 1997, citando a Denneny, 1979) de la palabra como vía que confiere sentido y durabilidad al mundo y para decir nuestra responsabilidad ante él. Para ella esta "responsabilidad queda ... vertebrada ... por tres elementos: ... Declarar la presencia de lo que está presente, declarase uno mismo ... y declarar un nexo entre sí y lo que está presente" (p. 27). Es este el circuito de la implicación, del saberse y sentirse interpelado por lo que sucede y asumir una posición responsable al respecto.

De cara a este horizonte de aspiración, se esbozan aquí, a modo de ejercicio y de invitación o provocación, tres líneas de trabajo que han sido minimizadas, banalizadas o de plano omitidas, en la mayoría de las prácticas educativas: El pensamiento crítico, la dimensión socioafectiva y la memoria con sentido ético- político. Lejos de pretender que sean las únicas, se plantean como ineludibles e íntimamente relacionadas entre sí. Si se enuncian separadas, ello responde solo a la necesidad de hacer los énfasis pertinentes para cada una. Su articulación, no secuenciada, sino simultánea, gira en torno al empeño por recuperar la capacidad de los sujetos en formación

\footnotetext{
${ }^{7}$ A fin de ilustrar esta situación de manera más concreta se menciona el caso de México: En los contenidos curriculares de la asignatura de Formación Cívica y Ética se omite tanto la noción de política como la de lo público, a pesar de que se mencionan con frecuencia en los libros de texto, pero no se aborda el trabajo sobre su significado.
} 
doi: http://dx.doi.org/10.15359/ree.22-2.17

URL: http://www.una.ac.cr/educare

CORREO: educare@una.cr

para involucrarse en los asuntos comunes y desarrollar la responsabilidad, entendida esta como "la capacidad para hacerse cargo del otro como otro y más allá de sí mismo" (Patiño, 2011, p. 66).

Estas tres líneas no son nuevas en la historia de las pedagogías críticas. De manera explícita o implícita se han contemplado desde las propuestas gestadas por la llamada escuela nueva hasta las pedagogías críticas descolonizadoras de América Latina que mucho se han nutrido del sustento ético, teórico y empírico de las prácticas de educación comunitaria alternativa, de las de organizaciones de la sociedad civil democratizante y hasta de los movimientos sociales, en especial, los emprendidos por la juventud en los últimos años (Fernández, 2014, 2015).

\section{El pensamiento crítico al servicio del desarrollo del juicio político}

La política, señala Arendt (1997), "siempre ha tenido que ver con la aclaración y la disipación de los prejuicios" (p. 52) y estos carecen de evidencia en tanto que no son fruto ni de la experiencia, ni del vínculo personal. Dada la facilidad con que son aceptados por muchas personas que los asumen como irrefutables, el desafío está en crear condiciones para desarrollar un pensamiento crítico capaz de superar las formas de juzgar bajos principios declarados como universales que niegan lo propio de cada particularidad.

Si bien el desarrollo del pensamiento crítico ha aparecido como propósito en planes y programas de estudio de la educación básica, en los hechos se le castiga al poner en primer lugar la necesidad de que el estudiantado responda correctamente a las pruebas estandarizadas. Desde esta prioridad no hay tiempo para pensar y menos para pensar junto a las otras personas. Es el tiempo de las respuestas para obtener mayores puntajes y no ser del grupo excluido. Si esa presión no pendiera por igual sobre las cabezas de personal docente, directivo y alumnado, se podría recuperar el sentido del pensamiento crítico como un reconocimiento de que lo que existe no agota las posibilidades de la existencia. Una posible repolitización de las prácticas educativas formales, informales o no formales requiere de un pensar en términos críticos para negarse a aceptar como bueno lo que hay, pues se sospecha que puede haber algo que mejore lo existente.

Desde una lógica de la heteronomía, las prácticas educativas tradicionales han fortalecido la propensión a estar al servicio de la autoridad y la presión del grupo. Abonar la constitución de subjetividades autónomas supone abrir los espacios para que el estudiantado pueda desarrollar su capacidad para pensar sus opciones por sí mismo y junto a los otros sujetos cuando esté en juego aquello que competa al bien común más allá del simple intercambio de argumentos. Se trata, destaca Nussbaum en (Redacción: Parque Explora, 2015):

[De que los sujetos en formación aprendan] a examinarse a sí mismos y a pensar en las razones por las que son proclives a apoyar una cosa en lugar de otra - en lugar de, como sucede a menudo, ver el debate político simplemente como una forma de jactarse, o conseguir una ventaja para su propio lado. (p. 18) 
Hace falta promover formas de debate que permitan pasar de una visión antagónica de la otra persona diferente como enemiga, como competidora que amenaza con deslegitimar las propias demandas, para transformarla en un agonismo que reconduzca la confrontación a un modelo adversarial. "La dimensión antagónica está siempre presente, es una confrontación real, pero que se desarrolla bajo condiciones reguladas por un conjunto de procedimientos democráticos aceptados por los adversarios" (Mouffe, 2011 p. 28).

Así, a través del debate regulado por el respeto mutuo, el estudiantado podría, mediante esta forma de ejercicio del pensamiento crítico, poner a prueba la lógica de lo que escuchan e imaginar alternativas al pensar las cosas desde ángulos que vayan más allá de las verdades oficiales que legitiman el estado de cosas.

La opción porel agonismo, sostiene Mouffe (2011), ofrece un encuadre de intersubjetividad, el cual propicie que cada sujeto interlocutor asuma la responsabilidad por las posturas propias, reconstruya sus argumentos $y$, tal vez, hasta descubra que hay premisas compartidas con el otro ser "político" que resulta humanizado al ser reconocido como un ser racional.

\section{Dar lugar a la dimensión socioafectiva de la educación}

Dentro de esta tarea de superar las interacciones instrumentalizadas para rehumanizar la relación con el otro en el desarrollo del pensamiento crítico, el reconocimiento del eje de la dimensión socioafectiva se presenta como ineludible para "construir fuentes de emoción colectiva, porque la emoción es la fuente de las acciones humanas, y no la razón, que usamos sólo para regular las acciones. Lo que no nos emociona no nos apasiona ni nos compromete" (Silva, 2011, p. 90).

El frío juicio no alcanza para involucrar, para invitar a la búsqueda compartida de soluciones. Hace falta incorporar al análisis la noción de comprensión (Puig, 2003), esa que desata preguntas en busca de los detalles de la concreción, del caso particular para calibrarlos y sopesarlos, pues lo justo, lo correcto se construye de acuerdo con las posibilidades que ofrece cada situación; desde los propios prejuicios, significados, creencias, concepciones y, desde luego, desde la consideración y el ejercicio de la contrastar la propia mirada con las posiciones de las demás personas. El sujeto en formación y en especial aquellos individuos que pasan por experiencias de cambio e incertidumbre se ven con frecuencia presionados para imponerse modos de ser que les eviten el rechazo o la exclusión. Por ello requieren de condiciones para poder identificar y decidir en torno a aquello que consideran como "suyo" de modo que construyan una valoración de sí que les permita lidiar con obstáculos y conflictos sin caer en la negación de sí (Redacción: Parque Explora, 2015). 
doi: http://dx.doi.org/10.15359/ree.22-2.17

URL: http://www.una.ac.cr/educare

CORREO: educare@una.cr

Hoy, las pedagogías de la crueldad que se impulsan desde los medios nutren el morbo, la curiosidad por el sufrimiento del otro ser y hacen de la muerte un espectáculo.

La pedagogía de la crueldad no es más que el acostumbramiento al dolor, a que el mundo es cruel, la compasión no tiene por qué ser parte del paisaje. La televisión antes no mostraba las formas de crueldad que se ven hoy a las tres de la tarde en las pantallas. Antes se contaba que había una muerte, hoy se muestra el morir, la saña, se muestran aspectos que antes no eran visibles. Todo eso es parte de la política del acostumbramiento a la muerte. (Segato, en Toso, 2016, párr. 16)

Por ello, hace falta pensar una contrapedagogía de la crueldad que se haga cargo de la formación de sujetos políticos y deje atrás la idea de formar solo al sujeto prudente y autónomo para entenderlo desde una posición de alteridad, como negociador de sentidos $y$, por tanto, como un esfuerzo de construcción con otras personas en el encuentro con el mundo en un acto de autoesclarecimiento, como señala Carvalho (2004). El sujeto será, entonces, aquel capaz de reconocer a los otros individuos como sujetos, como iguales con quienes hila la misma trama. Ello demanda una dialéctica de la alteridad, un dislocarse en relación con el otro ser y luego volver a sí siendo otro. Frente a las redes de muerte del sujeto, es preciso vigorizar las otras, las que afirman las redes de la vida, las de las solidaridades, las que se orientan a otros mundos posibles, las que fortalecen la emergencia de prácticas emancipadoras que dan sentido a la experiencia societal y al necesario encuentro a través del diálogo, pero sabiendo diferenciar cuándo es mercantilización del encuentro; cuándo es segregación y cuándo encuentro humano.

\section{La memoria con sentido ético-político}

Toda forma de sociedad se basa más o menos en prejuicios mediante los cuales se incluye o excluye a otros seres. Los prejuicios, en especial aquellos que se esgrimen contra la política, son peligrosos. Alguna vez fueron juicios que se anclan en un pasado que oculta algo y que, al ser formulados por los grupos ganadores, impiden la experiencia del presente. Al constituirse estos prejuicios en "cosmovisiones homogéneas donde todo está previsto; en ideologías iluminadoras que pretenden abarcar toda la realidad histórica y política" (Arendt 1997, p. 55), protegen de toda experiencia. De hecho, añade Arendt (1997), frente a la imposibilidad de la política, occidente optó por transformarla en una historia universal que desdibuja la pluralidad en aras de una idea de humanidad como sujeto. Si hemos de asignar un papel central a la pluralidad, habrá que reconocer, junto con Levinas (citado por Bárcena y Mèlich, 2000), que la subjetividad deviene humana "no solamente cuando el sujeto ... es capaz de decidir cómo debe ser y cómo orientar su vida, sino también cuando es capaz de dar cuenta, además, de la vida del otro, cuando responde del otro, de su sufrimiento y de su muerte" (p. 142). 
Esta opción por el otro ser se sustenta, más que en un principio de autonomía o de libertad personal, en uno de responsabilidad, pues solo siendo responsables de la vida, de la muerte, del gozo y del sufrimiento de la otra persona, accedemos a la humanidad y "por eso la pregunta ética no es ¿Qué es el hombre?, sino ¿Dónde está tu hermano?". Y la respuesta inhumana es “No soy el guardián de mi hermano".

En el proceso del reconocimiento de la pertenencia a lo social se requiere de procesos de producción de sentidos de una existencia contextualizada, y reflexionada, pero también, para superar la dicotomía sujeto individual-sujeto social, hace falta recuperar la dimensión de subjetividad constituida a partir de la noción de historicidad, es decir, del sujeto afectado por la historia, en el reconocimiento de su condición temporal, no solo de su vida personal sino como integrante de la especie. Ello da lugar a una alteridad radical como efecto de un ejercicio de memoria que trasciende los límites del ciclo vital individual para sentir como propias las afrentas y crímenes de lesa humanidad a lo largo de la historia de la especie.

Conviene para ello recordar (Benjamin, citado por Löwy, 2002) que la historia la escriben los grupos que ganan, por eso hay que leerla a contrapelo para recuperar la memoria de los grandes sectores derrotados, de las víctimas que ocuparán así su lugar como criterio de interpretación de la historia.

La memoria nos es legada a través de crónicas que apuntan a la reconstrucción de acontecimientos que no hemos experimentado en carne propia, pero que nos competen y nos abren la posibilidad de romper la historia y mostrar que los derechos de los grupos vencidos siguen vigentes. No basta con la autonomía, ni la acción comunicativa, se requiere también de una razón anamnética, una razón que se sostenga en la capacidad de preservar los recuerdos, pues son el referente para cuestionar los discursos del poder deshumanizante que fortalece el deseo de control y se expresa en una pedagogía de la programación, de la evaluación, de la previsibilidad.

Imaginar una pedagogía rehumanizante supone, entonces, buscar en el recuerdo sus principios fundamentales para generar nuevas sensibilidades ancladas también en nuevas solidaridades que den sostén y sentido a una ética de la vigilancia o de la atención, de modo que, recordando el pasado sin venganza, podamos prestar más atención al presente, a fin de evitar, para el futuro, la normalización de la ceguera moral.

\section{A modo de conclusión}

En el marco de un cambio de época que parece haber declarado la imposibilidad del fin del capitalismo, ahora en una fase de despojo y precarización de la vida y el empleo, la tarea de la necesaria formación para la repolitización de la ciudadanía desde edades tempranas se ofrece como una tarea harto difícil, pero no imposible. Aún frente a la enorme falta de segurabilidad y de confianza en las instituciones; del incremento de la corrupción y la violencia 
sistémica, se ha fortalecido la capacidad de indignación, de organización y de elaboración de proyectos alternativos. Muestra de ello son las experiencias y propuestas desplegadas por jóvenes, docentes, grupos investigadores y en general por profesionales de la educación que, por ejemplo, en América Latina se inscriben en las llamadas pedagogías disidentes. Aún con la fuerza que ha adquirido el enfoque productivista de la educación, ha ido ganando terreno en las políticas educativas el reconocimiento del desarrollo del pensamiento crítico y de la inclusión de la dimensión socioafectiva. Queda aún pendiente, en la propia práctica educativa,

el fortalecimiento de las capacidades deliberativas y del desarrollo de sujetos conscientes de que su presente se encuentra afectado por la historia, una que incluya la memoria de las grandes poblaciones derrotadas a fin de generar nuevas sensibilidades y nuevas solidaridades.

\section{Referencias}

Abreu, E. (2007). Popol Vuh. Antiguas leyendas del Quiché. México: Grandes Letras.

Agamben, G. (2006). Homo Sacer. El poder soberano y la nuda vida I (2a reimpresión). Valencia: Pretextos.

Arendt, H. (1993). La condición humana. Barcelona: Paidós.

Arendt, H. (1997). ¿Qué es política? Barcelona: Paidós

Ávalos, G. (2015). La estatalidad en transformación. México: UAM, Xochimilco

Bárcena F. y Mèlich, J.-C. (2000). La educación como acontecimiento ético. Barcelona: Paidós.

Bauman, Z. (2001). En busca de la política. Argentina: FCE.

Bauman, Z. y Donskis, L. (2015). Ceguera moral. La pérdida de sensibilidad en la modernidad líquida. México: Paidós.

Beck, U. (1998). La sociedad del riesgo. Hacia una nueva modernidad. Barcelona: Paidós.

Butler, J. (2004). Vida precaria. El poder del duelo y la violencia (Trad. F. Rodríguez). Buenos Aires: Paidós. Recuperado de https://psicanalisepolitica.files.wordpress.com/2014/10/butlerjudith-vida-precaria.pdf

Calvo, D. N. (2003). Organización política auto-referenciada en sectores populares. El caso de la Federación de Tierra, Vivienda y Hábitat. Buenos Aires, CLACSO. Recuperado de bibliotecavirtual.clacso.org.ar/ar/libros/becas/2002/mov/calvo.pdf

Carvalho, I. (Junio, 2004). Globalización, subjetividad y resistencia. En El Debate sobre el sujeto. Foro Llevado a cabo en Cátedra Alain Touraine Universidad Iberoamericana Puebla, Puebla, Pue. 
Casa África. (s. f.) El Ubuntu hecho persona. Recuperado de http://www.casafrica.es/MCA MAndela 8971.jsp

Castro M. I., Rodríguez A. y Smith, M. (2014). La construcción ciudadana en la educación media superior. México: UNAM.

Cullen, C. (2003). La construcción de un espacio público como alternativa a la violencia social en el contexto de la globalización. En M. Feldfeber (Comp.), Los sentidos de lo público. Reflexiones desde el campo educativo (pp. 27-46). Argentina: Ediciones Novedades Educativas.

Dussel, E (29 de enero, 2014) 16 tesis sobre economía política [Video YouTube]. Recuperado de https://www.youtube.com/watch?v=4LngCCiSiNc

Encuesta Mundial de Valores. (2005). Análisis de datos en línea. Recuperada de http://www. wvsevsdb.com/wvs/WVSAnalizelndex.jsp

Fernández, A. C. (2010). Formación ciudadana e identidad. Voces de la sociedad civil. México: Universidad Pedagógica Nacional.

Fernández, A. C. (2014). Formación ciudadana: Jóvenes y acción social. Revista Electrónica de Investigación Educativa, 16(1). Recuperado de https://redie.uabc.mx/redie/article/ view/684/863

Fernández, A. C. (2015). Los jóvenes y las nuevas formas de acción colectiva. El caso de la Acampada Sur en el centro de Coyoacán. Revista Mexicana de Opinión Púlblica, 18, 71-90. doi: https://doi.org/10.1016/S1870-7300(15)71361-X

IFE (2014). Informe país sobre la calidad de la ciudadanía en México. México: IFE. Recuperado de http://www.contraloria.cdmx.gob.mx/docs/InfPaisCalidadCiudadania.pdf

León, D.y Delacoste, G. (10 de mayo, 2016). Hay que empezar de nuevo. Entrevista con Boaventura de Sousa Santos. La Diaria. Recuperado de http://alice.ces.uc.pt/news/?p=5530

Lizcano, E (2010). Imaginario colectivo y análisis metafórico. En A. M. Morales (Ed.). Territorios ilimitados: El imaginario y sus metáforas (pp. 3-26). México: Universidad Autónoma de Morelos-Azcapotzalco.

Löwy, M. (2002). Walter Benjamin: Aviso de incendio. Una lectura de la tesis "sobre el concepto de historia". Argentina: FCE.

Mazorco, G. (2010). Educación en crisis. Polis, 25, 1-17. doi: https://doi.org/10.4067/S0718$\underline{65682010000100016}$ 
doi: http://dx.doi.org/10.15359/ree.22-2.17

URL: http://www.una.ac.cr/educare

CORREO: educare@una.cr

Monedero, J. C. (2013). Curso urgente de política para gente decente. Madrid: Planeta. Recuperado de http://www.cronicon.net/paginas/Documentos/JC Monedero-Curso Urgente de Politica.pdf

Mouffe, C. (2011). En torno a lo político. Buenos Aires: FCE

Patiño, S. (2011). La capacidad ético-responsiva frente a la diferencia. En J. Espinoza (Coord.), Educación y eticidad. Reflexiones en las distancias. Homenaje a Teresa Yuren Camarena (pp. 53-71). México: Juan Pablos Editor.

Puig, J. M. (2003). Prácticas morales. Una aproximación a la educación moral. Barcelona: Paidós.

Redacción: Parque Explora. (14 de diciembre de 2015). Discurso de Marth Nussbaum al recibir el doctorado honoris causa en UdeA. Canal Cultura. Recuperado de https://canalcultura. org/2015/12/14/discurso-de-martha-nussbaum-al-recibir-el-doctorado-honoris-causaen-udea/

Santos, B de S. (16, noviembre, 2014). Carta a las y los jóvenes de México. La Jornada. Recuperado de http://www.jornada.unam.mx/2014/11/16/politica/009a1pol

Segob, Inegi. (2012). Quinta encuesta nacional sobre cultura política y prácticas ciudadanas ENCUP 2012. México: Autor. Recuperado de http://www.encup.gob.mx/en/Encup/ Documentacion 2012

Silva, J. (2011). Hacia el 'día después del desarrollo'. Descolonizar la comunicación y la educación para construir comunidades felices con modos de vida sostenibles. Campina Grande, Paraíba, Brasil: ALER. Recuperado de http://www.iepala.es/IMG/pdf/ALER Hacia el Dia Despues del Desarrollo -Jose de Souza Silva.pdf

Toso, C. (18 de septiembre, 2016). Rita Segato: La construcción del otro como antagónico es letal. enredando. Recuperado de http://www.enredando.org.ar/2016/09/18/rita-segatola-construccion-del-otro-como-antagonico-es-letal//

Touraine, A. (2000). ¿Qué es la democracia? Buenos Aires: Fondo de Cultura Económica.

Yurén, M. T. (2013a). Ciudadanía y educación. Ideales, dilemas y posibilidades de la formación éticopolítica. México: UAEM, Juan Pablos Editor.

Yurén, M. T. (2013b). Ética profesional y praxis. Una revisión desde el concepto de "agencia". Perfiles Educativos, 35(142), 6-14. Recuperado de http://www.scielo.org.mx/pdf/peredu/ v35n142/v35n142a16.pdf

Žižek, S. (2010). Sobre la violencia. Seis reflexiones marginales. Buenos Aires: Paidós. 